\title{
Role of offset and gradient architectures of 3-D melt electrowritten scaffold on differentiation and mineralization of osteoblasts
}

Naghmeh Abbasi ${ }^{1} 2^{*}$, Saso Ivanovski ${ }^{3}$, Karan Gulati ${ }^{3}$, Robert M. Love ${ }^{1}$ and Stephen Hamlet ${ }^{1,2^{*}}$ (D)

\begin{abstract}
Background: Cell-scaffold based therapies have the potential to offer an efficient osseous regenerative treatment and PCL has been commonly used as a scaffold, however its effectiveness is limited by poor cellular retention properties. This may be improved through a porous scaffold structure with efficient pore arrangement to increase cell entrapment. To facilitate this, melt electrowriting (MEW) has been developed as a technique able to fabricate cell-supporting scaffolds with precise micro pore sizes via predictable fibre deposition. The effect of the scaffold's architecture on cellular gene expression however has not been fully elucidated.
\end{abstract}

Methods: The design and fabrication of three different uniform pore structures (250, 500 and $750 \mu \mathrm{m})$, as well as two offset scaffolds with different layout of fibres $(30$ and 50\%) and one complex scaffold with three gradient pore sizes of 250-500 - $750 \mu \mathrm{m}$, was performed by using MEW. Calcium phosphate modification was applied to enhance the PCL scaffold hydrophilicity and bone inductivity prior to seeding with osteoblasts which were then maintained in culture for up to 30 days. Over this time, osteoblast cell morphology, matrix mineralisation, osteogenic gene expression and collagen production were assessed.

Results: The in vitro findings revealed that the gradient scaffold significantly increased alkaline phosphatase activity in the attached osteoblasts while matrix mineralization was higher in the $50 \%$ offset scaffolds. The expression of osteocalcin and osteopontin genes were also upregulated compared to other osteogenic genes following 30 days culture, particularly in offset and gradient scaffold structures. Immunostaining showed significant expression of osteocalcin in offset and gradient scaffold structures.

Conclusions: This study demonstrated that the heterogenous pore sizes in gradient and fibre offset PCL scaffolds prepared using MEW significantly improved the osteogenic potential of osteoblasts and hence may provide superior outcomes in bone regeneration applications.

Keywords: Melt electrowriting (MEW), Pore size, Scaffold, Polycaprolactone (PCL), Bone differentiation

\footnotetext{
* Correspondence: naghmeh.abbasi@griffithuni.edu.au;

naghme.k@gmail.com; s.hamlet@griffith.edu.au

${ }^{1}$ School of Dentistry and Oral Health, Griffith University, Gold Coast Campus,

Southport, Queensland 4215, Australia

Full list of author information is available at the end of the article
}

(c) The Author(s). 2019 Open Access This article is distributed under the terms of the Creative Commons Attribution 4.0 International License (http://creativecommons.org/licenses/by/4.0/), which permits unrestricted use, distribution, and reproduction in any medium, provided you give appropriate credit to the original author(s) and the source, provide a link to the Creative Commons license, and indicate if changes were made. The Creative Commons Public Domain Dedication waiver (http://creativecommons.org/publicdomain/zero/1.0/) applies to the data made available in this article, unless otherwise stated. 


\section{Introduction}

Bone lesions that results from fracture, infections and tumors require targeted strategies for effective clinical treatment [1]. The combination of a three-dimensional scaffold combined with growth factors and/or cells has significant potential in bone tissue engineering as an ideal bone substitute option. However such scaffolds are not widely applied in clinical medicine, with the inability to seed a large enough cell population into scaffolds being one key impediment [2]. A desirable porous interconnected scaffold is required to allow uniform cell diffusion and distribution throughout the entire scaffold structure [3]. Many studies have attempted to solve this problem with various approaches, such as using bioreactors for enhanced cell proliferation, chemical and biological surface modification and varying the pore size of the scaffolds in a coordinated fashion to geometrically represent a cross section of a bone defect for an individual patient as a result of trauma or cancer metastasis [4-7]. Notably, previous studies showed that cell differentiation is influenced by the porosity, elasticity and stability of the scaffold [8].

Melt electrowriting scaffold fabrication enables precise control of the porosity, pore morphology and pore size of the printed scaffold architecture [9]. This allows predictable strain and stress distribution within the scaffold, which can be further optimized to produce an environment favouring higher cell infiltration through appropriate interconnectivity within the scaffold and subsequent vascularization and angiogenesis [10].

Previous studies have shown rapid bone formation was associated with pore sizes between 290 and $310 \mu \mathrm{m}$. While smaller pore sizes enhance the mechanical properties of the scaffold, the optimal size for vascularization was noted to be $\sim 400 \mu \mathrm{m}[11,12]^{\cdot}$ Therefore, fabrication of a 'gradient' porous scaffold, whereby the pore size gradually increases from one layer to the next, may overcome some of the individual limitations of both small and large homogeneous pore size scaffolds.

Gradient structures provide macropores suitable for vascularization, efficient gas/waste diffusion and nutrient supply at the expense of reduced mechanical stability. However, the denser structure of a heterogeneous gradient architecture improves ion signalling and protein adsorption as well as mechanical properties of the scaffolds, such as compressive strength. Additionally, they facilitate greater protein adsorption and better cell adhesion which decreases in the larger pore size of a homogeneous scaffold [13]. Interestingly, the gradient scaffold architecture is similar to the natural structure of native bone tissue that represents different mineral density from cancellous bone to cortical bone [14, 15].

Furthermore, higher pore size in gradient scaffolds has been shown to enhance permeability, cell migration, as well as sufficient nutrients and oxygen tension in larger pores and up-regulate osteopontin and collagen type I expression, thus generating more bone mass, vascularization and blood vessel ingrowth while inhibiting the formation of cartilaginous tissue in the regenerating sites [16, 17]. On the other hand, the smaller size of gradient pores promote cell seeding and growth by providing higher surface area [18].

The complex heterogeneous and hierarchical structure of bone tissue creates significant variation in the compressive and tensile strength of different regions within bone. It's been shown that the morphology of the pores influences the mechanical properties and the structure of the scaffolds i.e. with more complex morphological architectures, the compressive strength will be increased [19], however, the scaffolds with greater Young's modulus and smaller pore size are preferred in applications required to withstand greater loads [20]. According to Sobral et al., the simple architecture of homogeneous scaffolds is prone to collapse under high stress applied to the scaffolds, while the complexity of non-uniform porous scaffolds enables them to recover after deformation and maintain their elastic state which is critical for biomaterials implanted for bone applications [21].

Our previous studies have shown that, when compared to simpler homogeneous structures, scaffolds with offset and gradient architectures resulted in significantly higher cell proliferation following seeding (Additional file 1) [22]. As a logical extension of this work, this study will investigate the potential effects of heterogeneous porous scaffold architectures, particularly offset and gradient structures on osteogenic gene expression by osteoblasts seeded into these scaffolds and the rate of mineralization throughout the construct.

\section{Methods}

\section{Preparation of microfibrous PCL membrane}

A melt electrowriter (MEW) system was used to produce a fibrous scaffold with the fibre diameter in a range of $6-10 \mu \mathrm{m}$. The parameters for the components nozzle diameter, voltage, temperature and feeding rate were described in as previously reported [22]. Two different scaffold structures; homogeneous pore size $(250 \mu \mathrm{m}$, $500 \mu \mathrm{m}, 750 \mu \mathrm{m})$ and heterogeneous architecture including a tri-layer scaffolds with different pore sizes from $250 \mu \mathrm{m}$ on top, $500 \mu \mathrm{m}$ in the middle, and $750 \mu \mathrm{m}$ at the bottom of the scaffold and offset scaffolds in which layers were printed with various offset values of 30 and $50 \%$ compared to the previous layer (Fig. 1).

Subsequent calcium phosphate $(\mathrm{CaP})$ coating was perform using simulated body fluid (SBF). The surface modification was achieved in three steps; 1) pre-treatment of the samples in $1 \mathrm{M} \mathrm{NaOH}$ aqueous solution for surface activation for $0.5 \mathrm{~h} 2$ ) immersion of the samples in $10 \mathrm{X}$ 


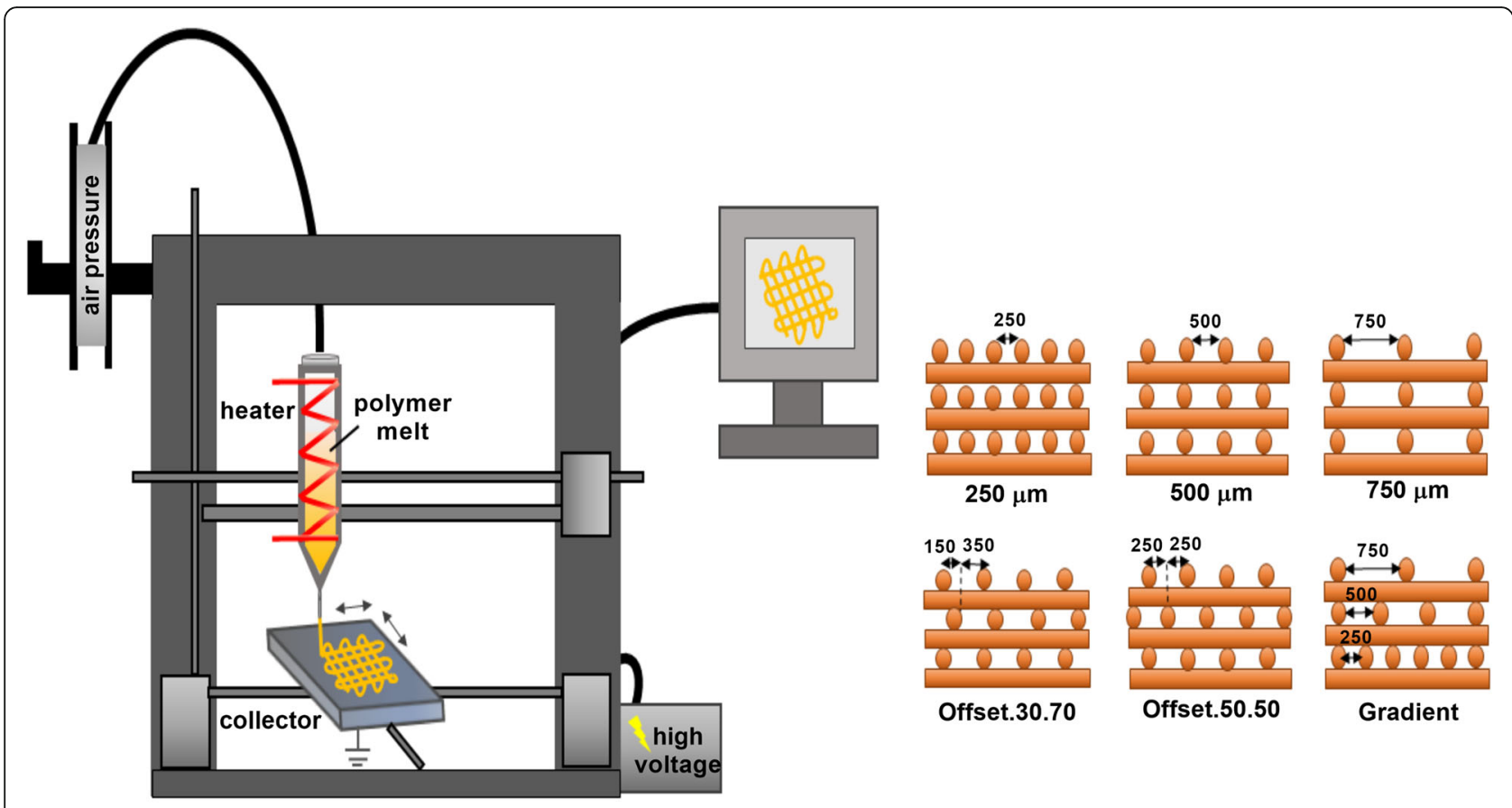

Fig. 1 Schematic illustrating the preparation of the scaffolds with different architectures by using MEW method

SBF at $37^{\circ} \mathrm{C}$ for $1 \mathrm{~h} 3$ ) soaking the samples in $0.5 \mathrm{M}$ $\mathrm{NaOH}$ for $0.5 \mathrm{~h}$ to obtain an uniform coating then rinsing with distilled water and allowing to dry.

\section{Cell culture}

Human osteoblast cells (hOB) obtaining from alveolar bone of a healthy female were seeded onto the scaffolds $\left(2 \times 10^{4}\right.$ in $\left.15 \mu \mathrm{l}\right)$ and cultured in either osteogenic or basal medium for 3,14 and 30 days, according to previously reported protocols [22].

\section{Scanning electron microscopy (SEM)}

Cell morphology after 30 days culture on the electrowritten scaffolds was captured by scanning electron microscopy (SEM). The substrates from cell culture were fixed in $3 \%$ glutaraldehyde, then dehydrated by treating in 0.1 $\mathrm{M}$ Cacodylate buffer three times, each $10 \mathrm{~min}$ and postfixed with $1 \%$ Osmium Tetroxide for $1 \mathrm{~h}$. After that, the specimens were washed in Milli-Q water two times, each $10 \mathrm{~min}$. The samples were then rinsed in a concentration gradient of ethanol (40-100\%) 10 min for each. To visualise cell penetration into the scaffolds, cross-sections of the samples were fragmented in liquid nitrogen in the middle stages of the dehydration process. Finally, hexamethyldisilazane (HMDS, Sigma Aldrich, UK) was used to replace the critical point drying step in biological samples for two times, each $30 \mathrm{~min}$. The samples were mounted on the $\mathrm{Al}$ stubs using adhesive carbon tapes and were Au-coated for observation by the SEM (Zeiss Sigma FESEM).

\section{Alkaline phosphatase (ALP) activity}

The concentration of alkaline phosphatase (ALP) in cells was measured after 3,14 and 30 days of culture using pnitrophenyl phosphate as a phosphatase substrate in a commercial Alkaline Phosphatase colorimetric assay Kit (Sigma Chemical, St. Louis, MO, USA) at a wavelength $405 \mathrm{~nm}$ according to the manufacturer's instructions. The ALP concentration was subsequently normalised to the total protein content (Quick Start Bradford protein assay, Bio-rad, Australia) of each sample.

\section{Alizarin red staining (ARS)}

To assess the osteogenic potential of the osteoblasts cultured in the melt electrowritten scaffolds with different pore sizes, alizarin red $\mathrm{S}$ staining of calcium deposited in the extracellular matrix of osteoblasts cultured on the scaffolds after 14 and 30 days was carried out. Briefly, the culture media was removed and the scaffolds washed using PBS. The cells within the scaffolds were fixed in $4 \%$ paraformaldehyde then placed in $500 \mu \mathrm{L}$ of Alizarin Red S solution $(40 \mathrm{mM})$ for $20 \mathrm{~min}$ at room temperature. After washing, the stained cells and scaffolds were imaged using an inverted phase contrast tissue culture microscope (Olympus, CKX 41, NY, USA). Quantification of these results was achieved by dissolving the samples in $1 \mathrm{~mL} 10 \%$ Cetylpyridinium Chloride for $1 \mathrm{~h}$ 
before transferring to 96 well plates and measuring the absorbance at $540 \mathrm{~nm}$ in a microplate reader (POLARstar Omega, BMG LABTECH, Germany). The average value of the negative controls (scaffold without cells) [22] was subtracted from the values of the corresponding experimental groups.

\section{Micro-computed tomography ( $\mu-\mathrm{CT}$ ) of cell-scaffold construct}

To further evaluate mineralisation within the cell-seeded scaffolds, $\mu-\mathrm{CT}$ analysis of constructs cultured in osteogenic differentiation medium was compared to the control group (basal medium) after 30 days of culture. The volume of mineralisation was measured by the $\mu$-CT software ( $\mu$ CT40, SCANCO Medical AG, Brüttisellen, Switzerland). The average value of the negative controls (cell seeded scaffolds in expansion media) was subtracted from the values of the corresponding experimental groups. The sample was put inside the tube containing deionised water so that, it was located at the bottom of tube and cotton wool was used to stop moving of sample during scanning process. The tube was sealed to prevent solution evaporation. For scanning, the high-resolution mode was selected and the X-ray tube was applied at $45 \mathrm{kVp}$ and $177 \mathrm{lA}$. Integration time was set to $300 \mathrm{~m} \mathrm{sec}$ and a three-fold frame averaging was applied using the same $\mu$-CT hardware, acquisition, and reconstruction parameters as above. Three-dimensional images of the scaffolds were reconstructed by the software package.

\section{Real-time PCR analysis (q-PCR)}

RNA was extracted from the osteoblast cells 14 and 30 days after seeding onto the scaffolds using a TRIzol extraction kit (Ambion, USA). Following cDNA synthesis from $100 \mathrm{ng}$ of total RNA (Taqman cDNA synthesis kit, Life Technologies, USA), the expression of osteopontin (opn), osteocalcin (ocn), bone morphogenetic protein 2 (bmp-2), alkaline phosphatase (alp), collagen type Ia ( $\mathrm{col} I a)$, wingless-related integration site (wnt) family member $3 \mathrm{a}$ (wnt3a), and wnt family member $5 \mathrm{a}(w n t 5 a)$ was achieved with an ABI 7900HT real-time PCR system (Life Technologies, USA) using SYBR Green Real-Time PCR Master Mix (Life Technologies, USA) and the following protocol; $3 \mathrm{~min}$ at $95^{\circ} \mathrm{C}$ for polymerase activation followed by $40 \mathrm{cy}$ cles of $10 \mathrm{~s}$ denaturation at $95^{\circ} \mathrm{C}, 20 \mathrm{~s}$ annealing at $58^{\circ} \mathrm{C}$, and $1 \mathrm{~s}$ extension at $72^{\circ} \mathrm{C}$. $\beta$-actin expression was used as a house keeping gene and for normalization of the data.

\section{Immunofluorescence staining}

For immunocytochemical analysis of the osteoblast cells cultured on different pore size PCL scaffolds (tissue culture plate acted as the control group) for 14 and 30 days, cells were fixed with $4 \%$ paraformaldehyde in PBS (Polysciences, Warrington, PA, USA) for $30 \mathrm{~min}$ at room temperature then gently rinsed with PBS. The cell membranes were then permeabilized and blocked with a protein blocker solution (1\% BSA, $22.52 \mathrm{mg}$ Glycine in $0.1 \%$ Tween 20 in PBS), Sigma Aldrich) for $30 \mathrm{~min}$. After washing, the cells were incubated in the following diluted primary antibodies at $4{ }^{\circ} \mathrm{C}$ overnight: mouse monoclonal anti-Collagen IA (1:250, SantaCruz Biotechnology, USA), rabbit polyclonal antiCollagen III (1:100, abcam, Australia), mouse monoclonal anti-Osteocalcin (1:200, abcam, Austrailia).

The cells were rinsed in PBS (three times, 5 min per wash) and incubated in the appropriate secondary antibody i.e. Alexa Fluor 488-conjugated goat anti-rabbit (1:200, abcam, Australia) or F (ab')2-Goat anti-Mouse IgG FITC (1:200, ThermoFisher Scientific, USA) at room temperature in the dark for $1 \mathrm{~h}$. Cell nuclei were stained using 40, 6-diamidino-2-phenylindole (DAPI, Vector Laboratories, Burlingame, CA, USA) in PBS (1:1000) for $30 \mathrm{~min}$. The samples were mounted onto glass slides for visualisation using a fluorescence microscope (Nikon, Eclipse- Ti, U.S.A).

\section{Statistical analysis}

Statistical analysis of any differences between means was performed using a two-way ANOVA with correction for multiple comparisons. The experiments were run in triplicate. A $p$-value of $<0.05$ was considered as statistically significant.

\section{Results}

\section{Cell-scaffold morphology}

Figure 2 SEM images show the morphology and pore arrangement of the MEW PCL scaffolds prior to cell seeding. Thirty days following seeding with osteoblasts, SEM images showed good attachment and growth of the osteoblasts onto the PCL scaffolds (Fig. 3a, b, c). Optimum cell attachment and proliferation was identified on the $250 \mu \mathrm{m}$ pore size homogeneous scaffold and the offset architecture scaffolds where the majority of cells appeared to be entrapped in the space between two displaced fibres in the offset groups. The $500 \mu \mathrm{m}$ and $750 \mu \mathrm{m}$ pore sizes appeared to be too large for the cells to interact with the scaffold fibers whereas in the gradient group the cells passed through the largest pore size at the top of scaffold then settled down into the smaller pores at the bottom of the construct (Fig. 3c)

Under lower magnification, information on the degree of scaffold mineralization and the position of the cells within this mineralized matrix after 30 days culture can be observed (Fig. 3a, b). Reflecting the cell attachment results, calcified matrix production occurred predominately on the offset and $250 \mu \mathrm{m}$ surface scaffolds. At higher magnification, globular shaped deposits could be distinguished in the vicinity of the more dense regions of cell-fibre junctions and in the smaller areas between the pores (Fig. 3c). In the gradient group, the cells appeared more concentrated at the bottom of scaffold 


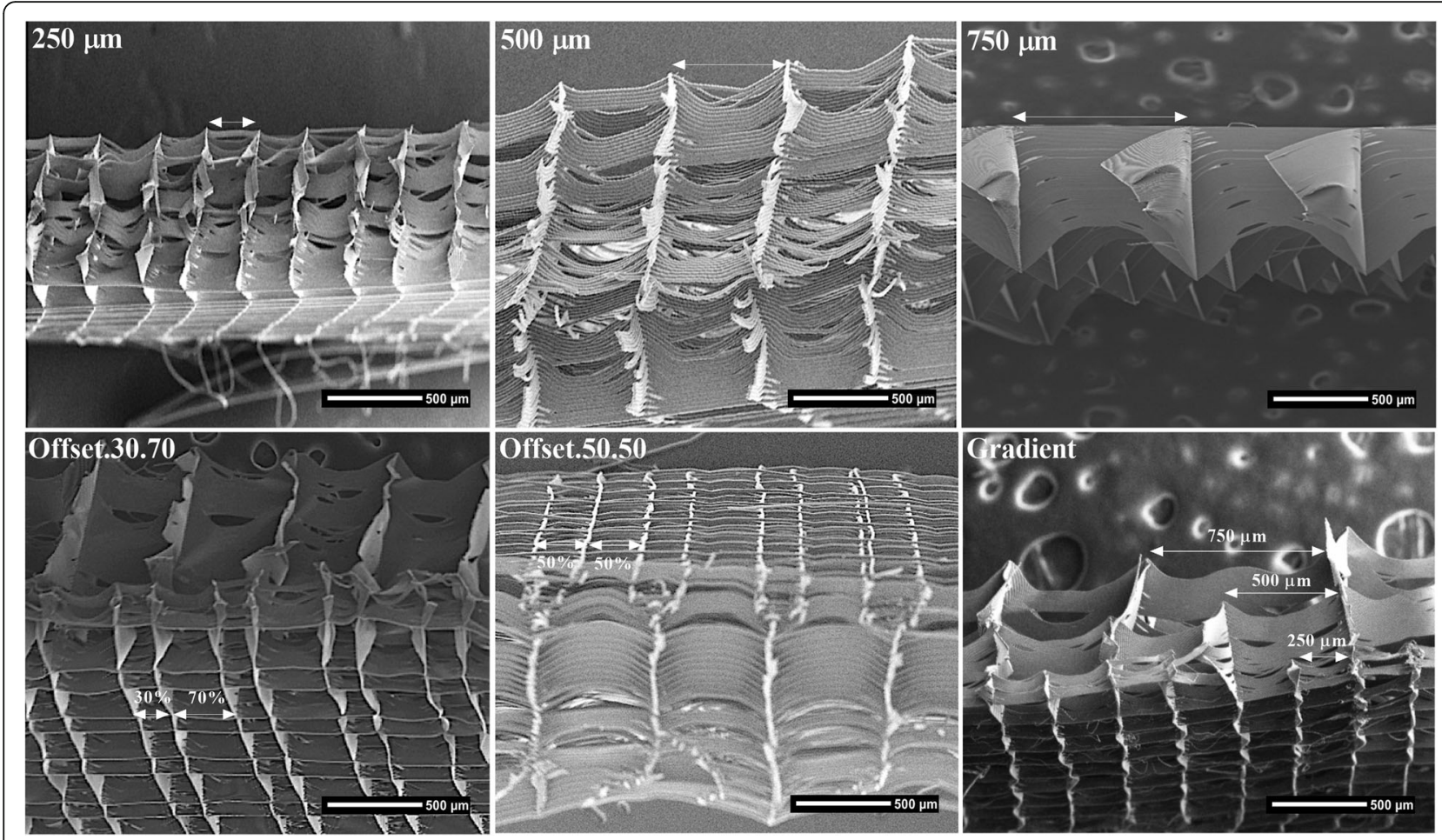

Fig. 2 SEM image of the porous scaffold structures

structure having passed through the large pore size at the top of scaffold and settled down into the smaller pores at the bottom of scaffold (Fig. 3d).

\section{Impact of porous scaffolds on ALP activity of osteoblast cells}

Alkaline phosphatase (ALP) activity was very low at day 3 in all groups (Fig. 4a, b) in the similar ranges between 0.7 to 3.1 that the maximum amount was displayed for gradient, $250 \mu \mathrm{m}$ and offset.30.70 scaffolds respectively. By day 14 ALP activity had increased in all groups with the highest levels of activity in osteoblasts cultured on the offset.50.50 and gradient scaffolds. However, it was peaked significantly for the gradient structure culturing in osteogenic media compare to the other groups. By 30 days of culture, a reduction of ALP activity was seen for all groups except the homogeneous $750 \mu \mathrm{m}$ pore size scaffolds.

\section{Influence of porous scaffolds on calcium deposition by osteoblast cells}

To assess mineralized matrix formation on the scaffold, analysis of calcium deposition was performed after 14 and 30 days of culture in osteogenic and basal medium (Fig. 5a, b). The analysis of alizarin red staining showed a significant difference in calcium accumulation in the scaffolds cultured in osteogenic differentiation medium compared to basal medium as the control group. The data indicated that all scaffolds were able to significantly induce osteogenic differentiation through the augmentation of calcium in the extracellular matrix. The calcium deposition started to appear after 14 days and gradually increased up to 30 days in osteogenic medium. Figures $5 \mathrm{c}$, d showed the quantitative analysis of mineralization in all of the groups where the average calcium deposition was higher on offset.50.50, offset.30.70 and $250 \mu \mathrm{m}$ PCL scaffolds respectively. The $750 \mu \mathrm{m}$ showed the lowest amount after 30 days.

\section{Impact of porous MEW scaffolds on osteoblast cells mineralization}

Figure 6 compares extracellular matrix mineralisation of osteoblasts seeded onto the scaffolds and cultured in osteogenic media with those cultured in basal media. As expected from the corresponding alizarin red staining data, mineralization was distributed within the pores of the scaffold (Fig. 6a). Consistent with the alizarin red staining, pixel quantification of the $\mu$-CT images (Fig. 6b) also confirmed that the offset.50.50 scaffold had the highest amount of mineralisation while the $750 \mu \mathrm{m}$ pore size scaffold showed the lowest level of mineralization.

\section{Effect of porous scaffolds on osteoblast gene expression of osteogenic markers}

Expression of the osteogenic markers col Ia, alp, ocn and opn, as well as the osteogenesis associated signalling molecules bmp-2, wnt3a and wnt5a, in osteoblasts cultured on the scaffolds were analysed by quantitative 


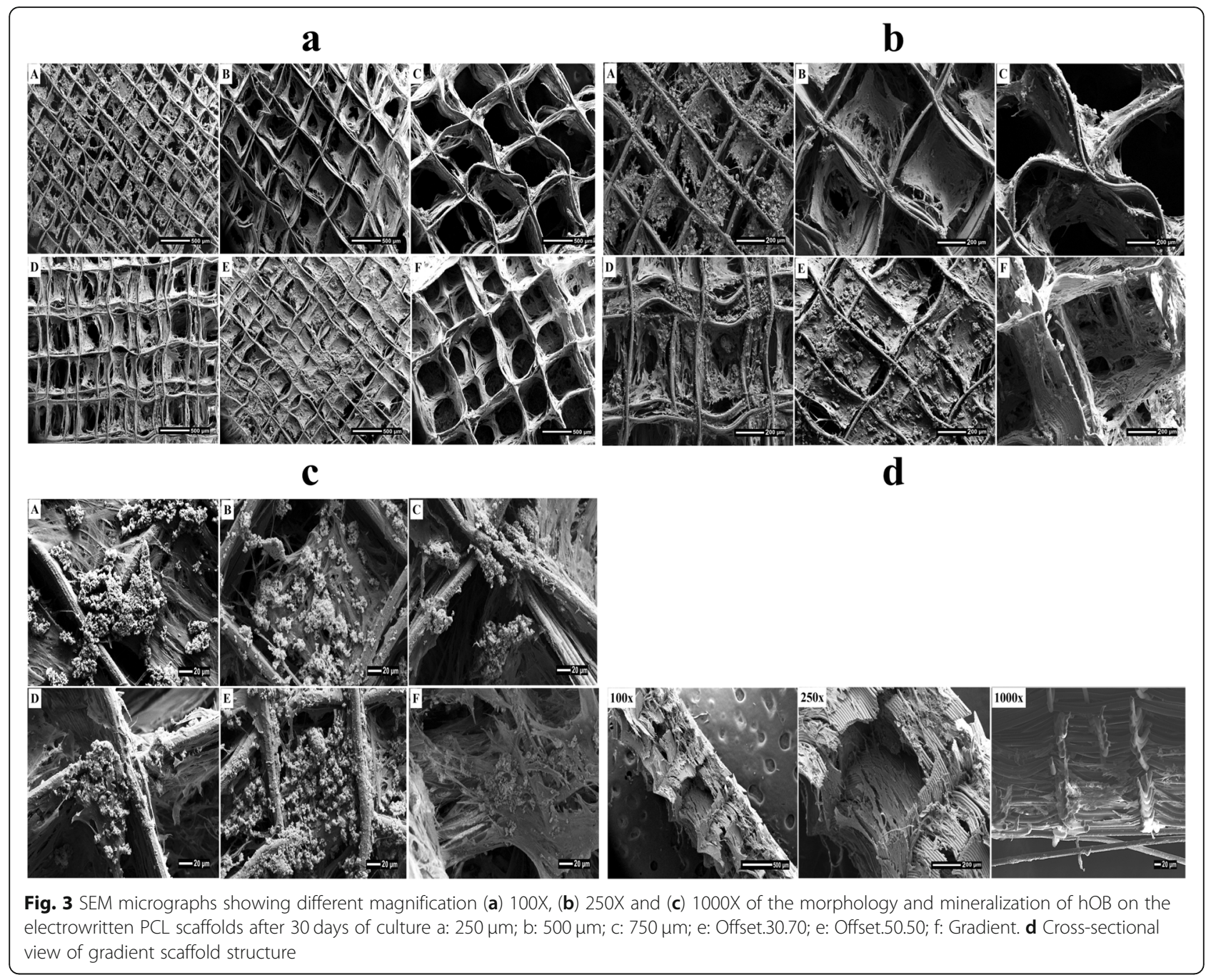

real-time PCR (Figs. 7, 8). After 14 days of culture in osteogenic medium, col Ia transcript levels were significantly higher compared to the other genes. Also, the expression of col Ia increased in offset.30.70 and 50.50 scaffolds on day 14. Among the different pore sizes, the gradient architecture induced the highest expression level of wnt5a and ocn. The expression of alp was not significantly different between the groups, except for $750 \mu \mathrm{m}$ which showed the maximum level, while the lowest expression was observed for offset.50.50. The alp expression was up-regulated in offset.30.70 and gradient scaffold groups, but this was not statistically significant compared to the other groups. Following 30 days of cell culture, the mineralization-related markers ocn and opn were up-regulated. In all groups, the expression of alp was less than ocn and opn after 30 days. Therefore, all of the scaffold groups stimulated the upregulation of alp and col I expression at early stages of osteogenic differentiation after 14 days, while, the gradient and offset.30.70 scaffolds were able to express ocn and opn. Increase of bmp2 gene expression was observed in $250 \mu \mathrm{m}$, offset.30.70 and gradient scaffolds, and at the highest quantity in the $750 \mu \mathrm{m}$ group, compared to other groups. The assessed data demonstrated the high expression of wnt5 in the gradient and 50.50 offset scaffolds.

\section{Osteoblast-related protein expression}

To evaluate the osteoconductivity of microporous melt electrospun PCL scaffolds, osteoblast cells were seeded on these scaffolds and cultured in osteogenic medium for 30 days in vitro. Immunocytochemistry was subsequently used to visualise collagen type I, collagen type III and osteocalcin deposition within the cellular matrix (Figs. 9, 10). Confocal microscopy demonstrated similar biocompatibility of the scaffolds as shown by the uniform spatial distribution of the cells on all six scaffold types. As expected, the images confirmed that collagen type I, collagen type III and osteocalcin were all expressed on all the scaffolds cultured in osteogenic media for 14 days and 30 days (Figs. 9, 10). These data 


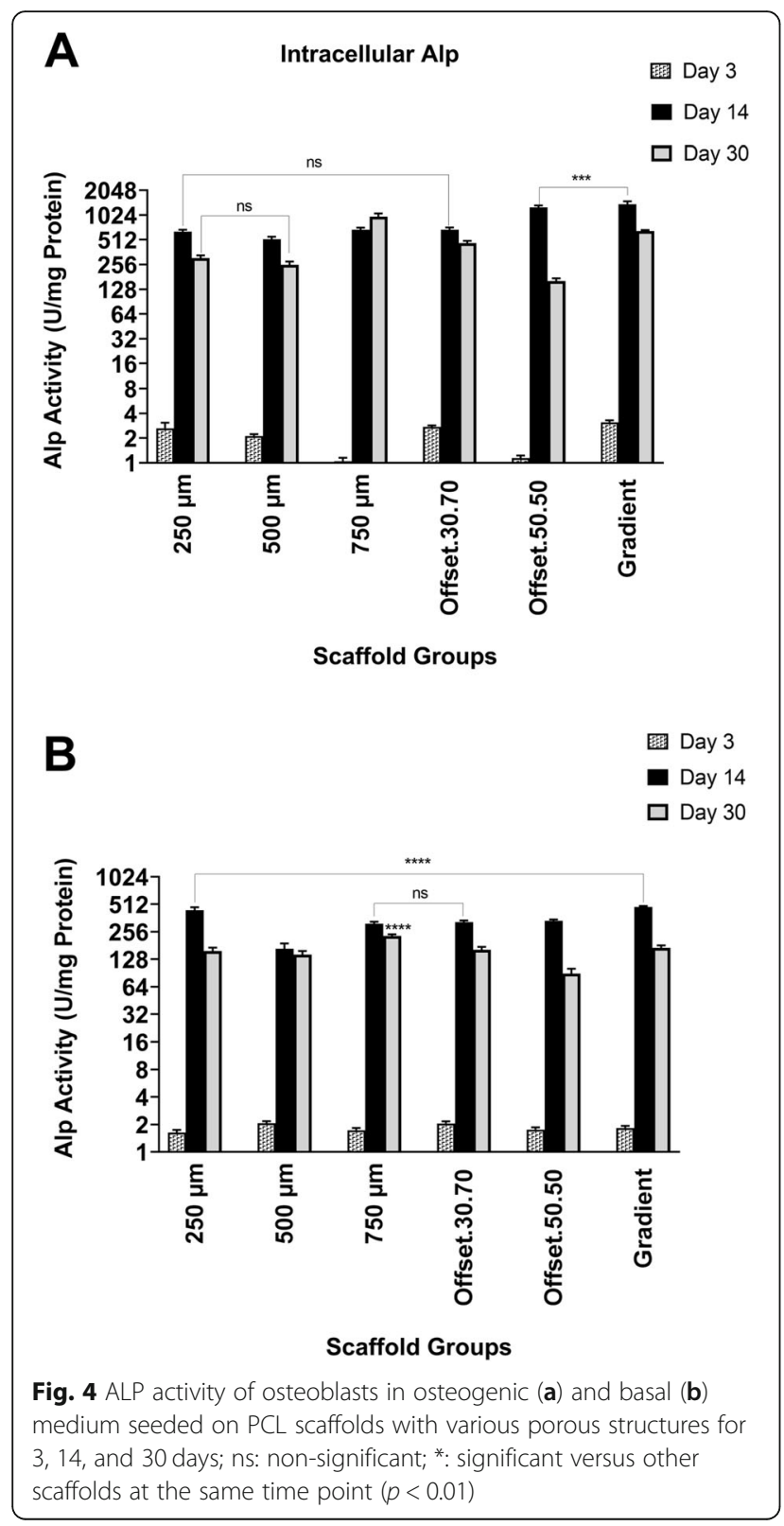

indicated that all of the scaffolds showed markedly better expression of osteocalcin compare to the other two proteins. It was obvious that the number of differentiated cells on the scaffolds increased with time. The pore spaces were filled and covered completely by the cells after 30 days, particularly in gradient and offset scaffolds. However, the expressions of collagen type I, collagen type III and osteocalcin on the scaffolds cultured in osteogenic media were much higher than those on the scaffolds cultured in basal medium (Figs. 9, 10).

\section{Discussion}

Several strategies can be utilized to attain porous scaffolds. As melt-electrowriting fabrication delivers a stable electrostatically drawn jet without whipping or random fibre deposition (as in solution electrospinning) it can be used for the formation of gradient structures mimicking native bone by precisely controlling fiber placement [23]. The proliferation and differentiation of cells within 3D scaffolds are affected by both the size and geometry of the scaffold's pores [24] but it's not clear however whether scaffolds with a uniform pore distribution of homogenous size, or constructs with a varying pore size distribution, are more suitable for bone regeneration applications. Therefore, the present study evaluated the effect of complex offset and graded porous structures on bone differentiation in contrast to the simpler homogeneous MEW PCL scaffolds.

According to the SEM observations, the presence of more anchorage points in offset and $250 \mu \mathrm{m}$ structures allowed more cells to populate and grow compared to the other scaffolds, suggesting that the smaller pore volume induced more cell aggregation. Porous scaffolds with an offset designs creates a higher surface area that could result in more cell distribution and proliferation. Since the fibres positioning affected the flow path of the media during cell seeding, the cell attachment efficiency increased. This is due to the presence of the 'obstacles' in the heterogeneous (offset/gradient) pore design, which provides cells with additional anchorage points during the seeding process [25]. The enhanced cell growth in the smaller pore size scaffolds may also be attributed to the higher concave surfaces and curvature of the small pore size than the large pore size which results in minimizing the surface area and surface tension [26, 27].

Surface tension or surface energy comes from the tendency of cells to approach each other to achieve a balanced energy i.e. neighboring cells have the least energy and the most stable state. This is the natural tendency of molecules to minimize their energy [28], therefore, to reduce their surface energy, the cells will select the corners of the pore space to enhance contact with the other cells. Because of the lower angle between the fibers of small pore sizes, it can provide a more suitable environment for the cells to interact with each other, thus minimizing their residual energy and becoming more stable $[29,30]$. . This could be the reason for higher cell proliferation and faster growth in the smaller pores of $250 \mu \mathrm{m}$ and offset.50.50 scaffolds with the higher curvature, compared to larger pore sizes of $750 \mu \mathrm{m}$.

While there are no experimental findings to support the hypothesis that minimal surface areas advance bone regeneration, concave surfaces compared to convex and planar surfaces have been shown to promote bone tissue regeneration, a process that increases with higher curvature $[20,31,32]$. This agrees with our study, which showed more mineralization in offset.50.50 and $250 \mu \mathrm{m}$ scaffolds compared to the higher pore size of scaffolds. 


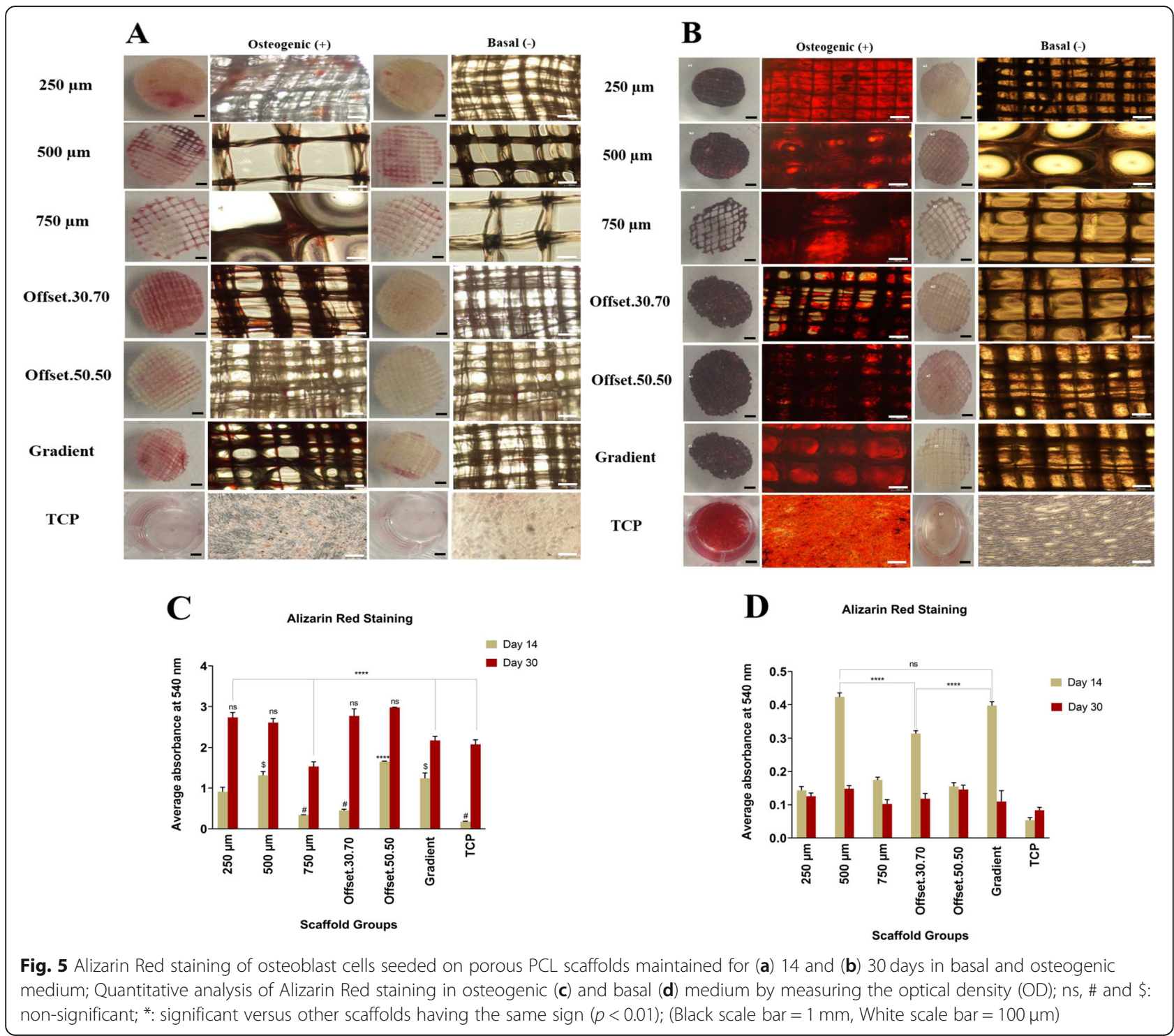

Cells at the centre of the pores have the highest energy levels, and larger pore sizes generate more perimeter and thus less curvature [33]. This may be the reason for low cell density with larger pore sizes despite more penetration of the cells into the $500 \mu \mathrm{m}$ and $750 \mu \mathrm{m}$ pore size scaffolds after $24 \mathrm{~h}$, compared to the $250 \mu \mathrm{m}$ pore size scaffold. The restriction on infiltration though promotes differentiation over proliferation since the inner space is filled faster due to more interactions between cells in the smaller area, while larger pore sizes have more empty spaces promoting proliferation instead.

Our results are in agreement with the study of Di Luca et al., that also showed an increase in cell number and mineralization by reducing the pore size to $500 \mu \mathrm{m}$ as well as in the area with the smallest pores $(500 \mu \mathrm{m})$ of a complex four zone gradient (500/700/900/1100 $\mu \mathrm{m}$ zones) using PEOT/PBT (poly (ethylene oxide therephtalate)/poly (butylene therephtalate) and PCL scaffolds fabricated by rapid prototyping [34]. They also showed that the variety in cell density in the different regions of gradient scaffolds could be attributed to the increase of hypoxia inducible factor (HIF) in the higher hypoxic regions of small pore size where the oxygen levels could drop [35]. Previous studies already suggested that rising hypoxia leads to osteochondrogenic differentiation, mediated via HIF-1 and triggered through the elevation of ALP and OCN levels and mineralization [36-39]. Interestingly, we also found more calcium mineralization in smaller pore sizes of $250 \mu \mathrm{m}$ and offset.50.50 structures.

Other models have shown that the behavior of cells can be affected by pore size. For example, chondrocytes produce large amounts of glycosaminoglycan (GAG) and collagen II in $400 \mu \mathrm{m}$ sized pores, while they proliferate in $200 \mu \mathrm{m}$ sized pores [40]. On the other hand, 


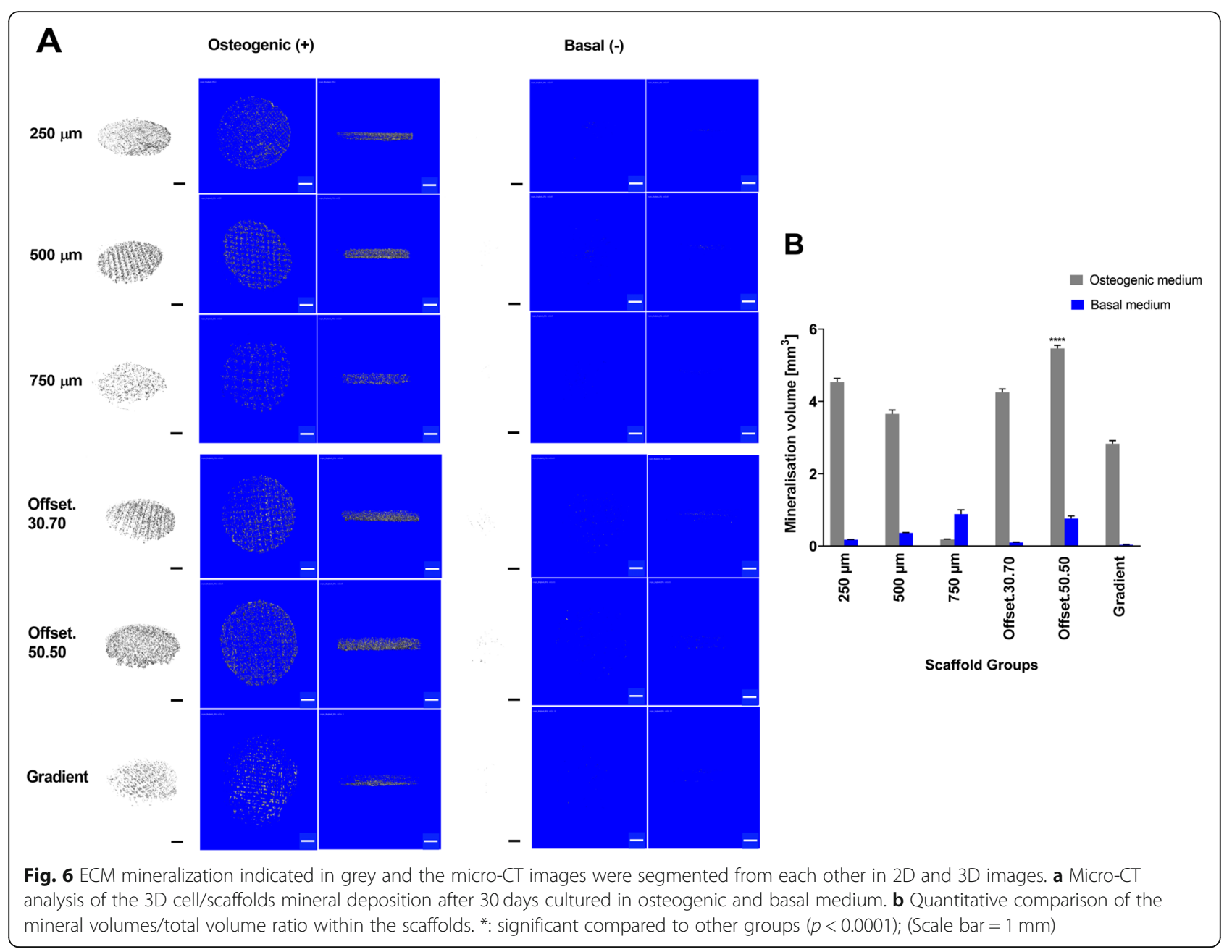

human mesenchymal stromal cells (hMSCs) seeded within PEOT/PBT scaffolds had significantly higher amounts of GAG in $500 \mu \mathrm{m}$ pore size (non-gradient) and gradient $(500-1100 \mu \mathrm{m})$ scaffolds, compared to largest pore sizes [41].

In the present study alkaline phosphatase activity, an early indicator of matrix mineralization, increased significantly after 14 days in the gradient and offset.50.50 scaffolds. After 30 days ALP activity decreased (compared to day 14) in all scaffolds, except for the $750 \mu \mathrm{m}$ pore size scaffold. This suggests that the structures with the greater porosity of $750 \mu \mathrm{m}$ and gradient architecture stimulate ALP expression. This finding is also in accordance with the in vitro study by Di Luca et.al (2016) which demonstrated that an increase in pore size of poly (ethylene oxide therephtalate)/poly (butylene therephtalate) (PEOT/PBT) and poly( $\varepsilon$-caprolactone) (PCL) scaffolds enhances ALP levels during human mesenchymal stromal cell differentiation [34].

Our study also showed that ALP levels were greater in $750 \mu \mathrm{m}$ scaffold after 30 days compared to the other scaffolds. This finding was in accordance with the study of Hutmacher et.al (2000) that indicated the structures with greater porosity could stimulate ALP expression, since countering hypoxic conditions in the smaller pore size and unavailability of $\mathrm{O}_{2}$ and nutrient supply for the cells [42]. Kasten et.al (2008) demonstrated that the higher porosity of 65 and $75 \% \beta$-tricalcium phosphate (TCP) ceramic scaffolds also enhanced ALP activity when compared to lower porosity (25\%) scaffolds due to better nutrient and $\mathrm{O}_{2}$ transportation [43]. However, it also needs to be acknowledged that the higher levels of ALP activity after 30 days in the present study might also be the consequence of less cells initially attaching to the larger pore structure of the $750 \mu \mathrm{m}$ scaffold.

Although higher porosity increased ALP activity, our results showed the offset scaffolds demonstrated superior matrix mineralization. This may be related to the surface wettability which increases surface free energy resulting in better cell attachment due to greater protein adsorption of ECM-products [44], and the rougher surface of the offset structures after calcium phosphate 

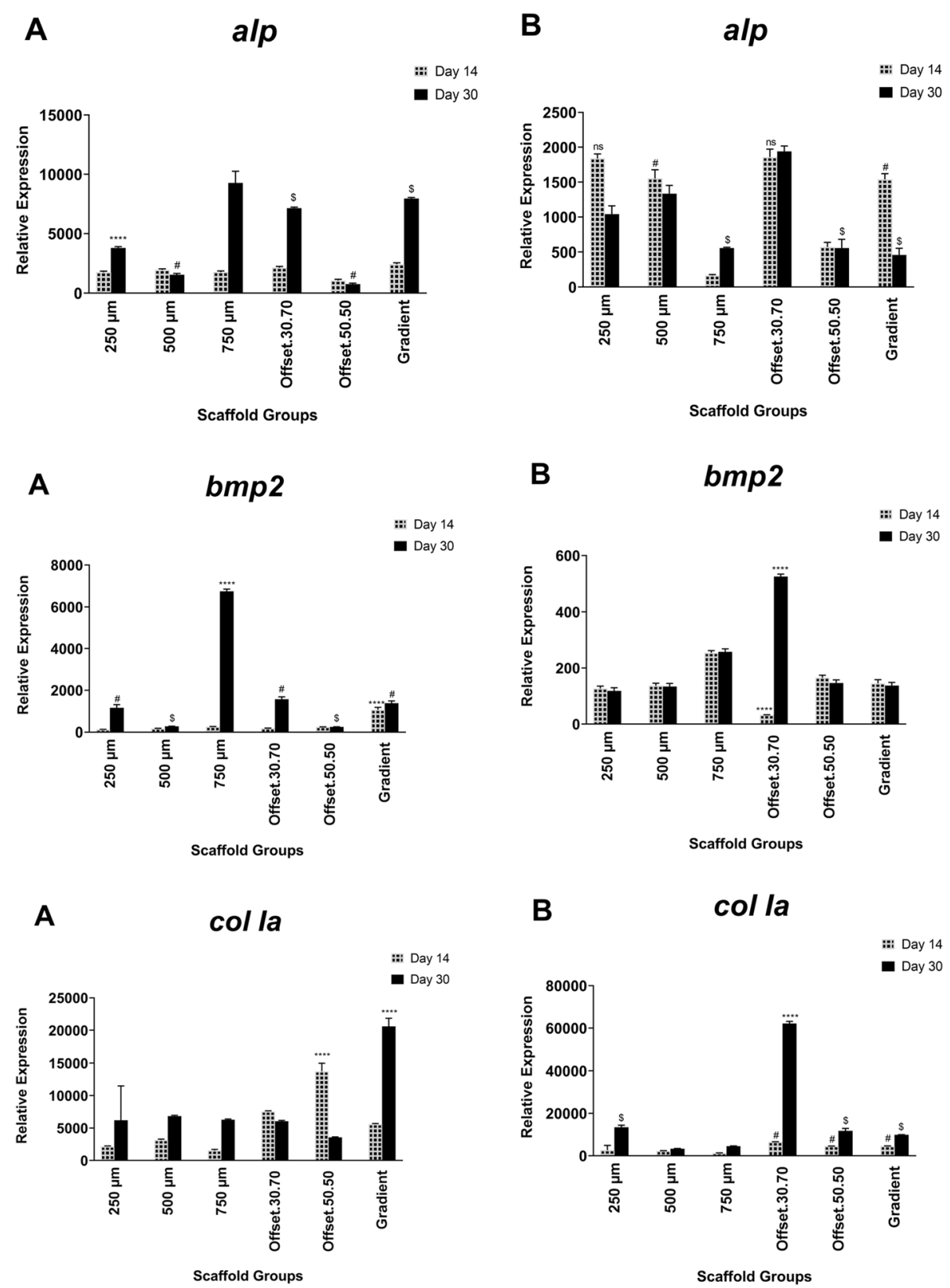

Fig. 7 Gene expression pattern during mineralization of human osteoblast cells seeded on PCL scaffold structures in osteogenic (a) and basal (b) medium for 3, 14, and 30 days Expression of genes was analyzed by real- time PCR and normalized to the levels of $\beta$-actin. ns, \# and \$: nonsignificant; *: significant versus other scaffolds having the same sign $(p<0.0001)$

$(\mathrm{CaP})$ coating modification, which was shown in our previous study by alizarin-red staining and surface area (BET) analysis [22]. It has been displayed the CaP coating on the surface of the fibres within the cells, that the higher level of mineralization was identified on the offset and then $250 \mu \mathrm{m}$ scaffold structures through alizarin-red staining and microCT analysis. This is in agreement with the study of Hammerl et al. (2019) that showed that CaP/PCL scaffolds formed a mineralized matrix regardless of the cell type cultured on these scaffolds [45], suggesting that released ions and wide contact area between the cells and fluids can evoke higher mineralization in short term cell culture, although evidence for this phenomenon is not yet provided. Although some studies have used the commercial materials to create a biologically active surface of the implant [46, 47]. For example, Tontowi et al. reported the combination of Hydroxyapatite powder (HA-200, brand name of CAMCERAM II HA) and the mixture of Gelatin/ Polyvinyl Alcohol (PVA) [HA/G/ PVA] fabricated by freeze-drying that resulted in the faster bone formation following 21 day of implantation [48]. 

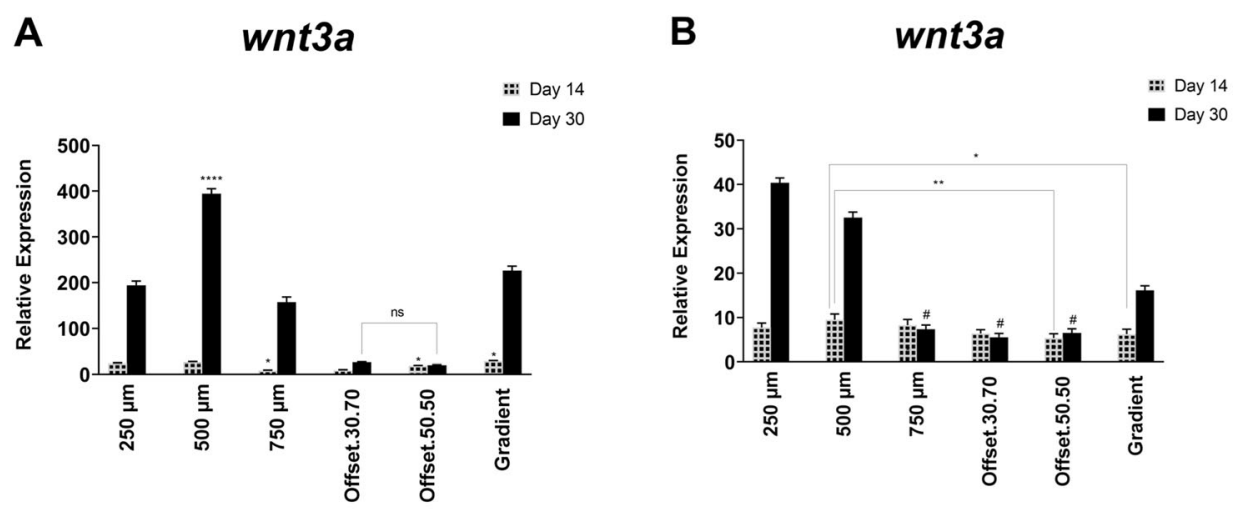

A

wnt5a
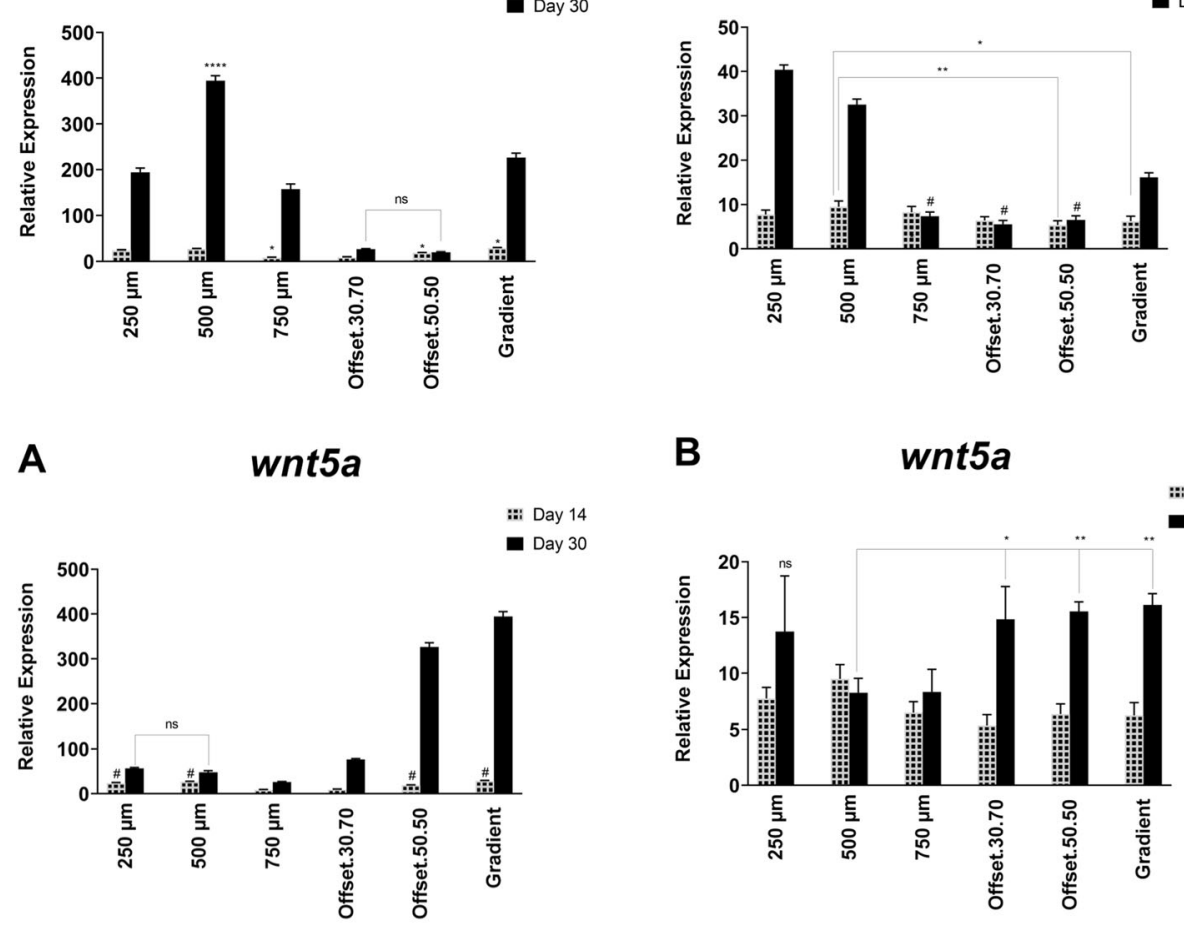

B

wnt5a

i:- Day 14

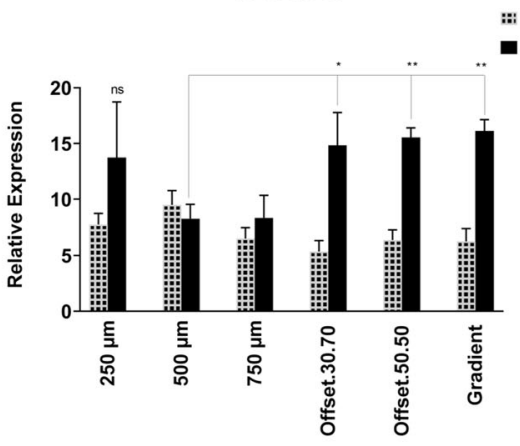

A

ocn

B
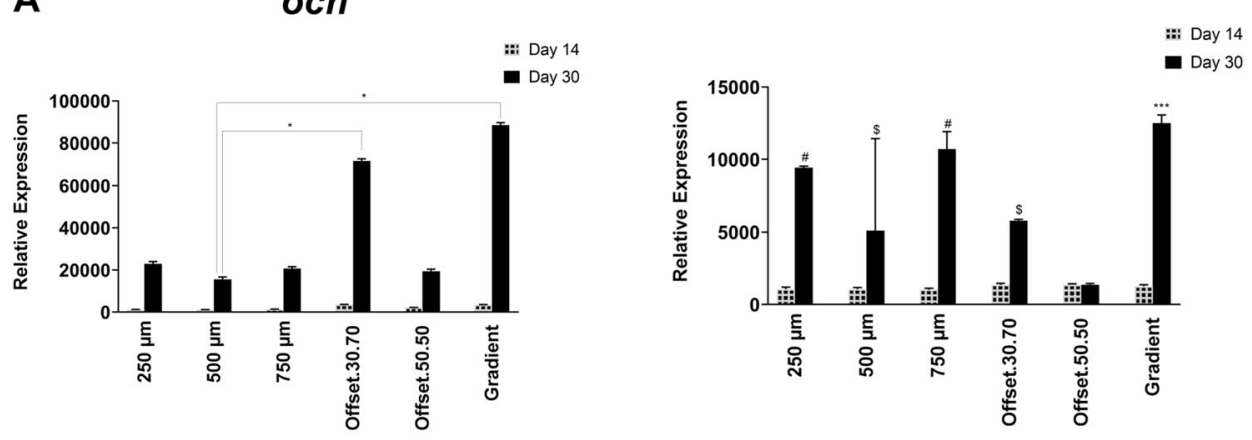

A

opn

B

opn

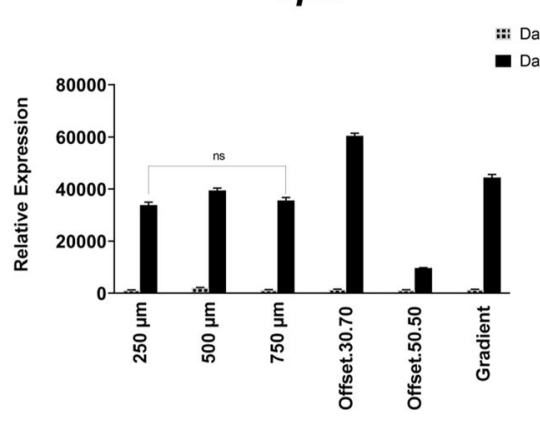

iii Day 14

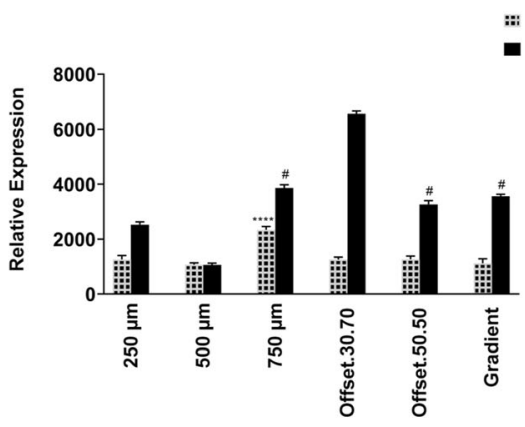

Scaffold Groups

Scaffold Groups

Fig. 8 Gene expression pattern during mineralization of human osteoblast cells seeded on PCL scaffold structures in osteogenic (a) and basal (b) medium for 3, 14, and 30 days Expression of genes was analyzed by real- time PCR and normalized to the levels of $\beta$-actin. ns, \# and \$: nonsignificant; *: significant versus other scaffolds having the same sign $(p<0.0001)$ 


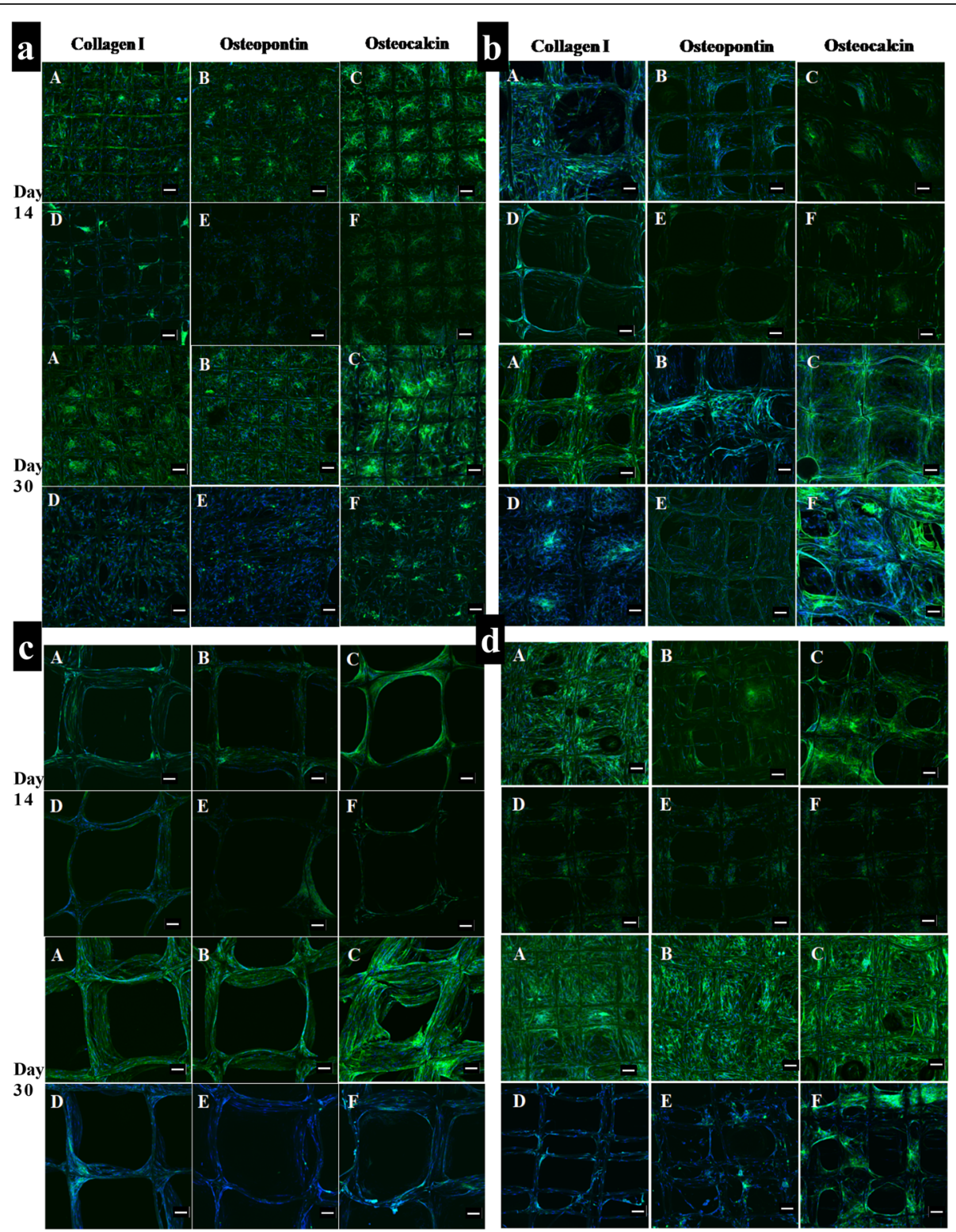

Fig. 9 Immunocytochemistry analysis of osteogenitor markers (collagen I, osteopontin and osteocalcin) for human osteoblast cells cultured in: (a,

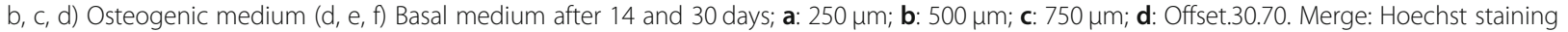
of the nucleus (blue), staining of the antibodies (green fluorescence); (Scale bar $=100 \mu \mathrm{m}$ )

The study of Yeo et al. (2012) also confirmed increased mineralization in 50 and $100 \%$ offset polycaprolactone (PCL) and $\beta$-tricalcium phosphate ( $\beta$-TCP) scaffolds compared to no-offset structures [25]. Furthermore, higher hydrophilicity creates more surface free energy that results in better cell attachment due to the greater protein adsorption as more ECM-products are achieved by higher cell number [44]. Our results indicated a high level of $\mathrm{col}$ Ia gene expression in offset scaffolds over 14 days, which were expressed at the middle stage of differentiation. Type I Collagen gene expression, an early marker of osteoblast differentiation which results in increased bone mass in combination with OCN and $ß$-catenin functions [49], as well as increased up-regulation of ocn gene expression was indeed seen in offset.30.70 scaffolds after 30 days. Increased bmp-2 gene expression was also observed in $250 \mu \mathrm{m}$, offset. 30.70 and gradient scaffolds with the highest expression in $750 \mu \mathrm{m}$ scaffolds. Activation of bmp signalling leads to osteocalcin and alkaline phosphatase expression [50] and after 30 days culture the activity of ALP increased in the $750 \mu \mathrm{m}$ scaffolds compared to the other groups, while bmp expression was not upregulated. 


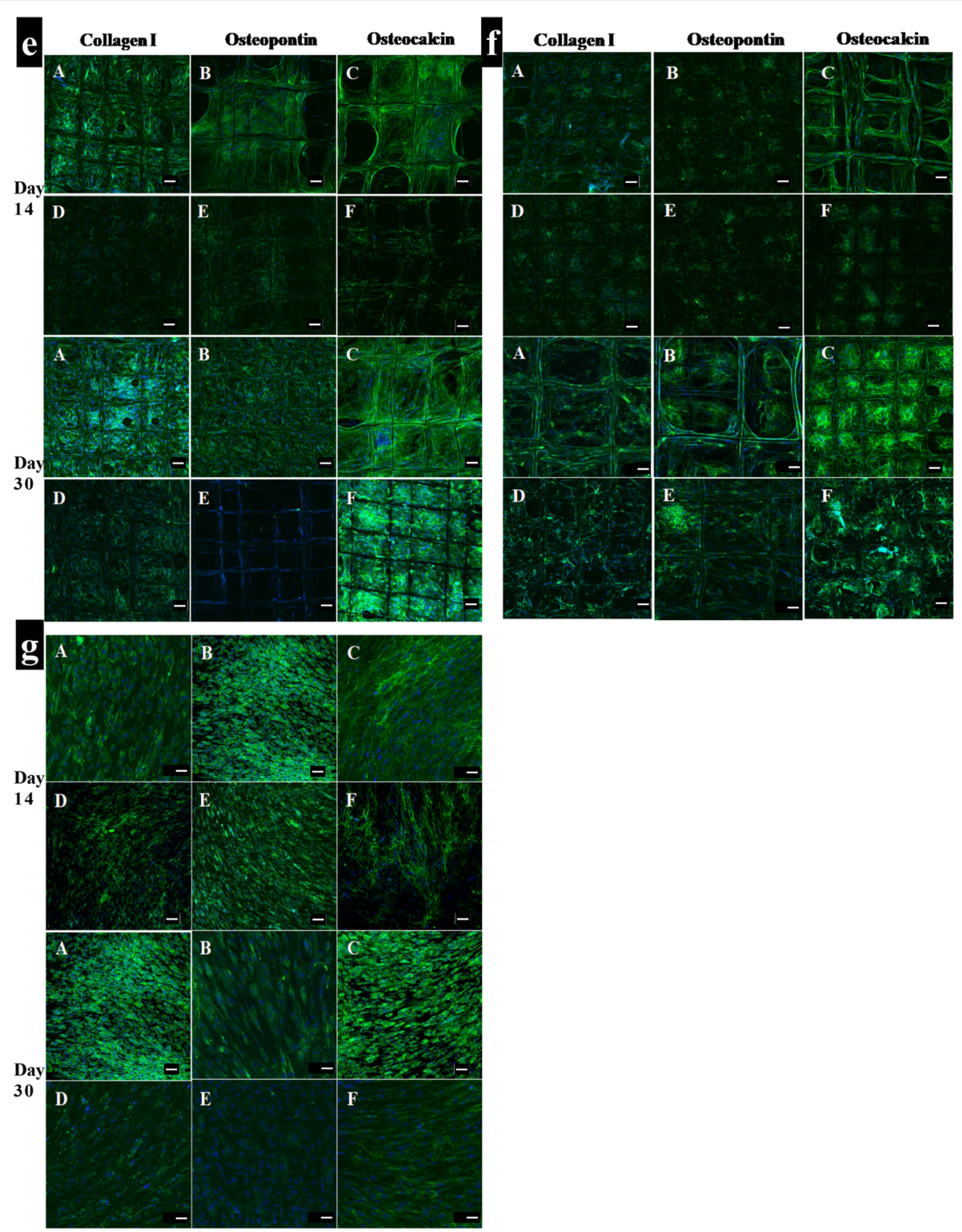

Fig. 10 Immunocytochemistry analysis of osteogenitor markers (collagen I, osteopontin and osteocalcin) for human osteoblast cells cultured in: ( $a, b, c)$ Osteogenic medium ( $d, e, f)$ Basal medium after 14 and 30 days; e: Offset.50.50; f: Gradient; g: Tissue culture plate (TCP). Merge: Hoechst staining of the nucleus (blue), staining of the antibodies (green fluorescence); (Scale bar = $100 \mu \mathrm{m}$ )

The gradient scaffolds also had a high level of wnt5 gene expression. The wht family of secreted glycoproteins plays a critical role in bone formation, mediated through the expression of osteoblast- specific genes. Activation of this pathway also results in the expression of alkaline phosphatase, an early osteoblast marker associated with the Wnt pathway [51]. The gradient scaffold was associated with the highest expression levels of wnt5 which correlated with increased alp expression in gradient scaffolds after 30 days of culture.

A previous study showed that up-regulation of bmp-2 supressed wnt3a signalling in MSCs and induced osteoblast differentiation [52]. Similarly, our results also showed higher expression of wnt3a in homogeneous $500 \mu \mathrm{m}$ scaffold compared to bmp2, which may mean that the cells in this scaffold were stimulated towards proliferation instead of differentiation, in contrast to gradient and offset scaffolds which had lower wnt3a expression.

High expression of ocn and opn is associated with the late stages of differentiation and mineralization [53, 54]. Offset and gradient scaffolds had greater expression of $o c n$ and opn, suggesting that these architectures enhanced osteoblast differentiation to exhibit the mature markers following 30 days. Sicchieri et al. (2012) also 
evaluated the effect of pore size on the osetogenic gene expression and showed that larger pore size of PLA-CaP scaffolds increased the expression of alp, type I col and ocn, similar to the higher expression of these markers in the gradient structure of this study, which may be influenced by the large pore size section in the gradient scaffold [55]. In the present study the increase in osteocalcin $(\mathrm{OCN})$ expression especially in offset scaffolds suggests that this architecture could promote osteogenesis as osteocalcin modulates the matrix mineralization which is a later phase of osteogenic differentiation [56]. The findings of this in vitro study need to be confirmed in an appropriate in vivo model, to fully elucidate the effect of heterogeneous and homogeneous pore size of melt electrospun $(\mathrm{MEW})$ scaffolds on bone regeneration.

\section{Conclusion}

This study has shown that heterogenous offset and gradient porous scaffolds are favourable structures for bone differentiation compared with uniform pore size scaffolds. The gradient architecture with three different pore sizes (250500-750 $\mu \mathrm{m}$ ) favoured ALP activity, while scaffolds with an offset $50 \%$ value allowed more matrix mineralization and the expression of late osteogenic markers, such as osteocalcin, which promoted maturation of differentiated osteoblasts. Also, both the gradient and offset scaffolds appeared to support ECM deposition in contrast to the homogeneous porous scaffolds. Taken together, the finding of this research demonstrated the gradient pore size and the offset architecture of MEW scaffolds are able to overcome the limitation of small and large uniform pore sizes associating with cell adhesion and mineralization during the in vitro bone differentiation process.

\section{Supplementary information}

Supplementary information accompanies this paper at https://doi.org/10. 1186/s40824-019-0180-z.

Additional file 1. Osteoblast Proliferation. Proliferation of osteoblasts in osteogenic ( + ) and basal medium (-) seeded on PCL scaffolds with different porosity for $1,3,14$, and 30 days. ${ }^{*}$ significant versus other scaffolds. $\Delta$ nonsignificant versus $250 \mu \mathrm{m}-$. \# and $\$$ nonsignificant versus Gradient - $(p<0.01)$; (Reproduced with permission from Abbasi et.al. doi: https://doi.org/10.1021/acsbiomaterials.8b01456).

\section{Abbreviations}

ALP: Alkaline phosphatase; ANOVA: Analysis of variance; ARS: Alizarin red staining; BET: Brunauer-Emmett-Teller; Bmp-2: Bone morphogenetic protein 2; CaP: Calcium phosphate; Col la: Collagen type la; DAPI: 6-diamidino-2phenylindole; GAG: GlycosaminoglycanGlycosaminoglycan; HIF: Hypoxia inducible factor; HMDS: Hexamethyldisilazane; hMSCs: Human mesenchymal stromal cellsstromal cells; hOB: Human osteoblast cells; MEW: Melt electrowriting; Ocn: Osteocalcin; Opn: Osteopontin; PCL: Poly( $\varepsilon$-caprolactone); PEOT/PBT: Poly (ethylene oxide therephtalate)/poly (butylene therephtalate; q-PCR: Real-time PCR analysis; SBF: Simulated body fluid; SEM: Scanning electron microscopy; TCP: Tissue culture plate; TCP: $\beta$-tricalcium phosphate; Wnt3a: Wingless-related integration site family member 3a; Wnt5a: Winglessrelated integration site family member 3a; $\mu-\mathrm{CT}$ : Micro-computed tomography

\section{Acknowledgments}

The authors acknowledge the assistance of the Institute of Health and Biomedical Innovation and the Central Analytical Research Facility at the Queensland University of Technology, Australia, for providing facilities and technical support used in this study.

\section{Authors' contributions}

NA was involved in the study design, fabricated the poly ( $\varepsilon$-caprolactone) scaffolds, conducted all in vitro studies, performed the related analyses, interpretation of the results, and drafted the manuscript. KG provided the SEM images and revised the manuscript. SI, RM-L and SH contributed to the conception and study design, interpretation of the results, and revised the manuscript for publication. All authors read and approved the final manuscript.

\section{Funding}

This study forms part of Naghmeh Abbasi's PhD research project who is supported by the School of Dentistry and Oral Health $(\mathrm{DOH})$ research grant within IPRS scholarship from Griffith University. Dr. Karan Gulati that was supported by the National Health and Medical Research Council (NHMRC) Early Career Fellowship (ECF), Peter Doherty-Australian Biomedical Fellowship (APP1140699).

\section{Availability of data and materials}

The datasets used and/or analyzed supporting the conclusions of current study are available and will be presented by the corresponding author on reasonable request.

\section{Ethics approval and consent to participate}

Not applicable.

\section{Consent for publication}

Not applicable.

\section{Competing interests}

The authors declare that they have no competing interests.

\section{Author details}

'School of Dentistry and Oral Health, Griffith University, Gold Coast Campus, Southport, Queensland 4215, Australia. ${ }^{2}$ Menzies Health Institute Queensland, Griffith University, Gold Coast Campus, Southport, Queensland 4215,

Australia. ${ }^{3}$ School of Dentistry, University of Queensland, Herston Campus, St Lucia, Queensland 4072, Australia.

Received: 28 October 2019 Accepted: 17 December 2019

Published online: 03 January 2020

\section{References}

1. Kargozar, S., et al., Bone Tissue Engineering Using Human Cells: A Comprehensive Review on Recent Trends, Current Prospects, and Recommendations. Appl Sci Basel, 2019. 9(1). http://https://doi.org/10.3390/ app9010174.

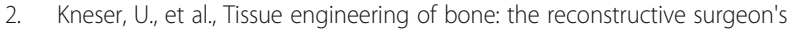
point of view. J Cell Mol Med, 2006. 10(1): p. 7-19. http:// https://doi.org/10. 1111/j.1582-4934.2006.tb00287.x.

3. Abdal-Hay, A., et al., Fabrication of highly porous biodegradable biomimetic nanocomposite as advanced bone tissue scaffold. Arab J Chem, 2017. 10(2): p. 240-252. http:// https://doi.org/10.1016/j.arabjc.2016.09.021.

4. Zhang, Z.Y., et al., A biaxial rotating bioreactor for the culture of fetal mesenchymal stem cells for bone tissue engineering. Biomater, 2009. 30(14): p. 2694-2704. http:// https://doi.org/10.1016/j.biomaterials.2009. 01.028 .

5. Tallawi, M., et al., Strategies for the chemical and biological functionalization of scaffolds for cardiac tissue engineering: a review. J R Soc Interface, 2015. 12(108). http:// https://doi.org/10.1098/rsif.2015.0254

6. Wu, D., et al., Development of a micro-tissue-mediated injectable bone tissue engineering strategy for large segmental bone defect treatment. Stem Cell Res Ther, 2018. 9(1): p. 331. http:// https://doi.org/10.1186/s13287018-1064-1. 
7. Tovar, N., et al., Form and functional repair of long bone using 3D-printed bioactive scaffolds. J Tissue Eng Regen Med, 2018. 12(9): p. 1986-1999. http:// https://doi.org/10.1002/term.2733.

8. Chocholata, P., V. Kulda, and V. Babuska, Fabrication of Scaffolds for BoneTissue Regeneration. Mater, 2019. 12(4). http:// https://doi.org/10.3390/ ma12040568.

9. Ameer, J.M., A.K. Pr, and N. Kasoju, Strategies to Tune Electrospun Scaffold Porosity for Effective Cell Response in Tissue Engineering. J Funct Biomater, 2019. 10(3). http:// https://doi.org/10.3390/jfb10030030.

10. Hrynevich, A., et al., Dimension-Based Design of Melt Electrowritten Scaffolds. Small, 2018. 14(22). http:// https://doi.org/10.1002/smll. 201800232

11. Oh, S.H., et al., In vitro and in vivo characteristics of PCL scaffolds with pore size gradient fabricated by a centrifugation method. Biomater, 2007. 28(9): p. 1664-1671. http:// https://doi.org/10.1016/j.biomaterials.2006.11.024.

12. Lo Re, G., et al., A facile method to determine pore size distribution in porous scaffold by using image processing. Micron, 2015. 76: p. 37-45 http:// https://doi.org/10.1016/j.micron.2015.05.001.

13. Cheng, M.Q., et al., A novel open-porous magnesium scaffold with controllable microstructures and properties for bone regeneration. Sci Rep, 2016. 6. http:// https://doi.org/10.1038/srep24134.

14. Chirchir, $\mathrm{H}_{\text {., }}$ Limited trabecular bone density heterogeneity in the human skeleton. Anat Res Int, 2016. 2016: p. 9295383. http:// https://doi.org/10. 1155/2016/9295383

15. Shi, D.J., et al., Preparation and properties of dopamine-modified alginate/ chitosan-hydroxyapatite scaffolds with gradient structure for bone tissue engineering. J Biomed Mater Res A, 2019. 107(8): p. 1615-1627. http:// https://doi.org/10.1002/jbm.a.36678.

16. Gupte, M.J., et al., Pore size directs bone marrow stromal cell fate and tissue regeneration in nanofibrous macroporous scaffolds by mediating vascularization. Acta Biomater, 2018. 82: p. 1-11. http:// https://doi.org/10. 1016/j.actbio.2018.10.016.

17. Murphy, C.M., et al., Effect of collagen-glycosaminoglycan scaffold pore size on matrix mineralization and cellular behavior in different cell types. J Biomed Mater Res A, 2016. 104(1): p. 291-304. http:// https://doi.org/10. 1002/jbm.a.35567.

18. Wang, S., et al., Pore functionally graded Ti6Al4V scaffolds for bone tissue engineering application. Mater Des, 2019. 168. http:// https://doi.org/10. 1016/j.matdes.2019.107643.

19. Cetinel, O., Z. Esen, and B. Yildirim, Fabrication, Morphology Analysis, and Mechanical Properties of Ti Foams Manufactured Using the Space Holder Method for Bone Substitute Materials. Metals, 2019. 9(3). http:// https://doi. org/10.3390/met9030340.

20. Boccaccio, A., et al., A Mechanobiology-based algorithm to optimize the microstructure geometry of bone tissue scaffolds. Int J Biol Sci, 2016. 12(1): p. 1-17. http:// https://doi.org/10.7150/ijbs.13158.

21. Sobral, J.M., et al., Three-dimensional plotted scaffolds with controlled pore size gradients: effect of scaffold geometry on mechanical performance and cell seeding efficiency. Acta Biomater, 2011. 7(3): p. 1009-1018. http:// https://doi.org/10.1016/j.actbio.2010.11.003.

22. Abbasi, N., et al., Effects of gradient and offset architectures on the mechanical and biological properties of 3-D melt Electrowritten (MEW) scaffolds. Acs Biomater Sci Eng, 2019. 5(7): p. 3448-3461. http:// https://doi. org/10.1021/acsbiomaterials.8b01456.

23. Tourlomousis, F., et al., Melt Electrospinning Writing Process Guided by a "Printability Number". J Manuf Sci Eng Trans Asme, 2017. 139(8). http:// https://doi.org/10.1115/1.4036348

24. Gregor, A., et al., Designing of PLA scaffolds for bone tissue replacement fabricated by ordinary commercial 3D printer. J Biol Eng, 2017. 11. http:// https://doi.org/10.1186/s13036-017-0074-3.

25. Yeo, M., C.G. Simon, and G. Kim, Effects of offset values of solid freeform fabricated PCL-beta-TCP scaffolds on mechanical properties and cellular activities in bone tissue regeneration. J Mater Chem, 2012. 22(40): p. $21636-$ 21646. http:// https://doi.org/10.1039/c2jm31165h

26. Riveline, D., et al., Focal contacts as mechanosensors: externally applied local mechanical force induces growth of focal contacts by an mDia1-dependent and ROCK-independent mechanism. J Cell Biol, 2001. 153(6): p. 1175-1185. http:// https://doi.org/10.1083/jcb.153.6.1175.

27. Zadpoor, A.A., Bone tissue regeneration: the role of scaffold geometry. Biomater Sci, 2015. 3(2): p. 231-245. http:// https://doi.org/10.1039/ c4bm00291a.
28. Jakab, K., et al., Relating cell and tissue mechanics: implications and applications. Dev Dyn, 2008. 237(9): p. 2438-2449. http:// https://doi.org/10. 1002/dvdy.21684.

29. Dierkes, U., et al., Minimal Surfaces, 2nd Edition. 2010. 339: p. Xi-+. http:// https://doi.org/10.1007/978-3-642-11698-8.

30. He, H.M., et al., Dynamic formation of cellular aggregates of chondrocytes and mesenchymal stem cells in spinner flask. Cell Prolif, 2019. 52(4). http:// https://doi.org/10.1111/cpr.12587.

31. Ambrosi, D. and F. Guana, Stress-modulated growth. Math Mech Solids, 2007. 12(3): p. 319-342. http:// https://doi.org/10.1177/1081286505059739.

32. Ambrosi, D. and A. Guillou, Growth and dissipation in biological tissues. Contin Mech Thermodyn, 2007. 19(5): p. 245-251. http:// https://doi.org/10. 1007/s00161-007-0052-y.

33. Fenchel, W., Curvature and twisting of enclosed space curves. Math Ann, 1929. 101: p. 238-252. http:// https://doi.org/10.1007/Bf01454836.

34. Di Luca, A., et al., Gradients in pore size enhance the osteogenic differentiation of human mesenchymal stromal cells in three-dimensional scaffolds. Sci Rep, 2016. 6. http:// https://doi.org/10.1038/srep22898.

35. Hsu, S.H., C.T. Chen, and Y.H. Wei, Inhibitory effects of hypoxia on metabolic switch and Osteogenic differentiation of human Mesenchymal stem cells. Stem Cells, 2013. 31(12): p. 2779-2788. http:// https://doi.org/10.1002/stem.1441.

36. Balogh, E., et al., Hypoxia triggers Osteochondrogenic differentiation of vascular smooth muscle cells in an HIF-1 (hypoxia-inducible factor 1)dependent and reactive oxygen species-dependent manner. Arterioscler Thromb Vasc Biol, 2019. 39(6): p. 1088-1099. http:// https://doi.org/10.1161/ Atvbaha.119.312509.

37. Mokas, S., et al., Hypoxia-inducible factor-1 plays a role in phosphateinduced vascular smooth muscle cell calcification. Kidney Int, 2016. 90(3): p. 598-609. http:// https://doi.org/10.1016/j.kint.2016.05.020.

38. Wagegg, M., et al., Hypoxia Promotes Osteogenesis but Suppresses Adipogenesis of Human Mesenchymal Stromal Cells in a Hypoxia-Inducible Factor-1 Dependent Manner. PLoS One, 2012. 7(9). http:// https://doi.org/10 1371/journal.pone.0046483.

39. Ichijima, T., et al., Osteogenic differences in cultured rat periosteal cells under hypoxic and normal conditions. Exp Ther Med, 2012. 3(2): p. 165-170. http:// https://doi.org/10.3892/etm.2011.393.

40. Lin, T.H., et al., Osteochondral Tissue Regeneration Using a TyramineModified Bilayered PLGA Scaffold Combined with Articular Chondrocytes in a Porcine Model. Int J Mol Sci, 2019. 20(2). http:// https://doi.org/10.3390/ ijms20020326.

41. Di Luca, A., et al., Influencing chondrogenic differentiation of human mesenchymal stromal cells in scaffolds displaying a structural gradient in pore size. Acta Biomater, 2016. 36: p. 210-219. http://https://doi.org/10. 1016/j.actbio.2016.03.014

42. Hutmacher, D.W., Scaffolds in tissue engineering bone and cartilage. Biomater, 2000. 21(24): p. 2529-2543. http://https://doi.org/10.1016/S0142 9612(00)00121-6

43. Kasten, P., et al., Porosity and pore size of beta-tricalcium phosphate scaffold can influence protein production and osteogenic differentiation of human mesenchymal stem cells: an in vitro and in vivo study. Acta Biomater, 2008. 4(6): p. 1904-1915. http:// https://doi.org/10.1016/j.actbio.2008.05.017.

44. Paterlini, T.T., et al., The role played by modified bioinspired surfaces in interfacial properties of biomaterials. Biophys Rev, 2017. 9(5): p. 683-698. http:// https://doi.org/10.1007/s12551-017-0306-2.

45. Hammerl, A., et al., A Growth Factor-Free Co-Culture System of Osteoblasts and Peripheral Blood Mononuclear Cells for the Evaluation of the Osteogenesis Potential of Melt-Electrowritten Polycaprolactone Scaffolds. Int J Mol Sci, 2019. 20(5). http:// https://doi.org/10.3390/ijms20051068.

46. Cooke, M.N., et al., Use of stereolithography to manufacture critical-sized 3D biodegradable scaffolds for bone ingrowth. J Biomed Mater Res Part B Appl Biomater, 2003. 64b(2): p. 65-69. http:// https://doi.org/10.1002/jbm.b.10485

47. Chua, C.K., et al., Development of tissue scaffolds using selective laser sintering of polyvinyl alcohol/hydroxyapatite biocomposite for craniofacial and joint defects. J Mater Sci Mater Med, 2004. 15(10): p. 1113-1121. http:// https://doi.org/10.1023/B:JMSM.0000046393.81449.a5.

48. Tontowi, A.E., et al., Biocomposite of Hydroxyapatite/Gelatin/PVA for Bone Graft Application. 2018 1st international conference on bioinformatics, Biotechnology, and Biomedical Engineering - Bioinformatics and Biomedical Engineering, 2018: p. 73-78. http:// https://doi.org/10.1109/BIOMIC.2018. 8610571 . 
49. Pflug, T., H.D. Uyen, and S. Rudloff, Reduced beta-catenin expression affects patterning of bone primordia, but not bone maturation. Biol Open, 2017. 6(5): p. 582-588. http:// https://doi.org/10.1242/bio.023572.

50. Wei, X.F., et al., Wnt and BMP signaling pathways co-operatively induce the differentiation of multiple myeloma mesenchymal stem cells into osteoblasts by upregulating EMX2. J Cell Biochem, 2019. 120(4): p. 65156527. http:// https://doi.org/10.1002/jcb.27942.

51. Sebastian, A., et al., Wnt co-receptors Lrp5 and Lrp6 differentially mediate Wnt3a signaling in osteoblasts. Plos One, 2017. 12(11). http:// https://doi. org/10.1371/journal.pone.0188264

52. Boyan, B.D., et al., Role of Wnt11 during Osteogenic differentiation of human Mesenchymal stem cells on microstructured titanium Surfaces. Sci Rep, 2018. 8. http:// https://doi.org/10.1038/s41598-018-26901-8.

53. Yodthong, T., et al., I-Quebrachitol Promotes the Proliferation, Differentiation, and Mineralization of MC3T3-E1 Cells: Involvement of the BMP-2/Runx2/MAPK/Wnt/-Catenin Signaling Pathway. Mol, 2018. 23(12). http:// https://doi.org/10.3390/molecules23123086

54. Liu, B.Y., et al., A protocol for isolation and identification and comparative characterization of primary osteoblasts from mouse and rat calvaria. Cell Tissue Bank, 2019. 20(2): p. 173-182. http:// https://doi.org/10.1007/s10561019-09751-0.

55. Sicchieri, L.G., et al., Pore size regulates cell and tissue interactions with PLGA-CaP scaffolds used for bone engineering. J Tissue Eng Regen Med, 2012. 6(2): p. 155-162. http:// https://doi.org/10.1002/term.422.

56. Carvalho, M.S., et al., Biomimetic matrices for rapidly forming mineralized bone tissue based on stem cell-mediated osteogenesis. Sci Rep, 2018. 8. http:// https://doi.org/10.1038/s41598-018-32794-4.

\section{Publisher's Note}

Springer Nature remains neutral with regard to jurisdictional claims in published maps and institutional affiliations.

Ready to submit your research? Choose BMC and benefit from:

- fast, convenient online submission

- thorough peer review by experienced researchers in your field

- rapid publication on acceptance

- support for research data, including large and complex data types

- gold Open Access which fosters wider collaboration and increased citations

- maximum visibility for your research: over $100 \mathrm{M}$ website views per year

At $\mathrm{BMC}$, research is always in progress.

Learn more biomedcentral.com/submissions 